\title{
Busca de Sensação e Condutas Anti-Sociais e Delitivas em Jovens
}

\author{
Sensation of seeking and antisocial \\ conducts and criminal in youngsters \\ Búsqueda de sensación y conductas \\ antisociales y delictivas en jóvenes
}

Nilton Soares Formiga Universidade Federal da Paraíba

Marcos Aguiar Universidade Federal do Rio de Janeiro

Alicia Omar Consejo Nacional de Investigaciones Científicas y Técnicas, Buenos Aires, Argentina
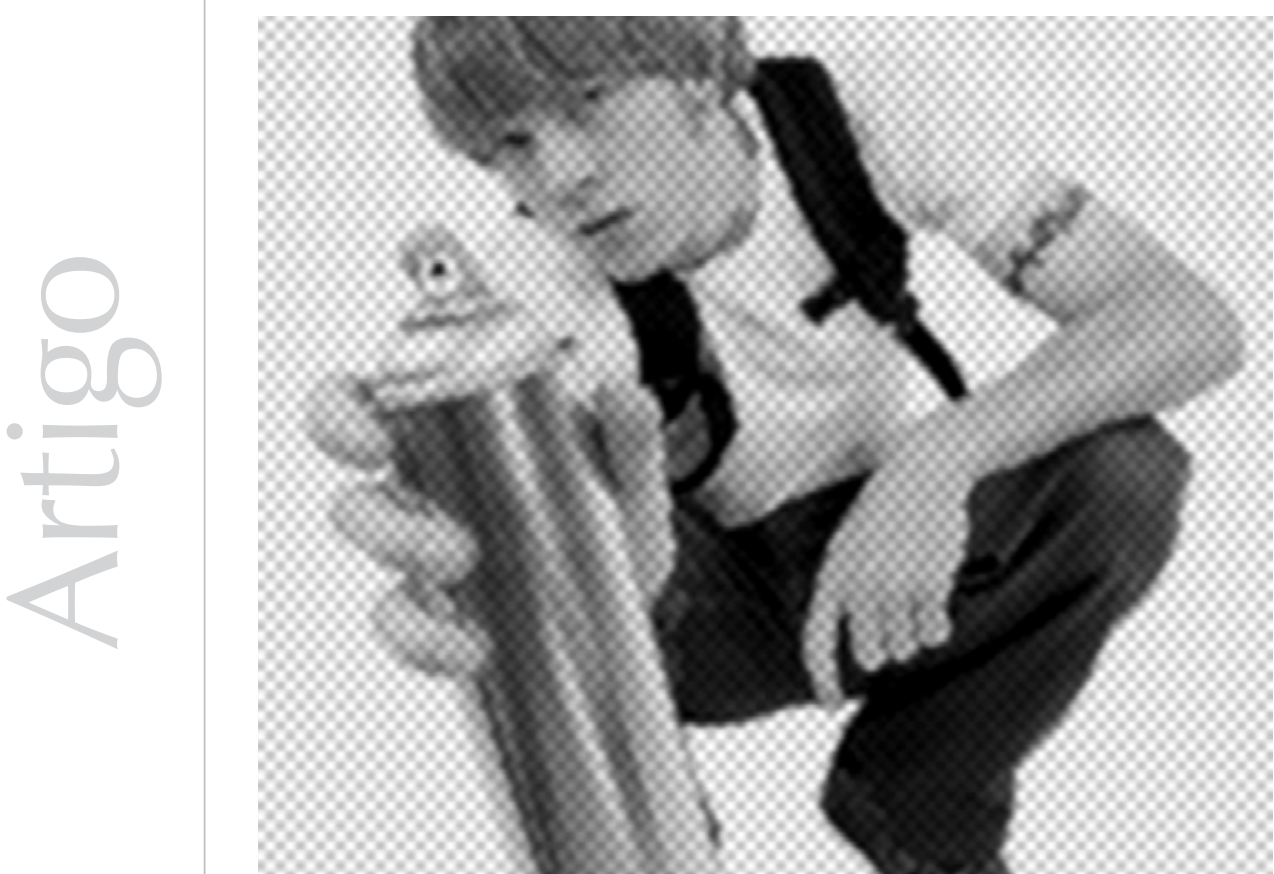
Resumo: O fenômeno das condutas juvenis tem sido alvo de interesse na ciência social e humana, principalmente aquelas que conduzem à delinqüência. Apesar de inúmeras variáveis conseguirem explicá-lo, o construto busca de sensações vem contribuindo muito para isso, pois ele enfatiza as diferenças individuais. A partir da perspectiva personalística, aponta a avaliação do grau com que os jovens pretendem viver experiências em correr riscos e sua predisposição a sensações de novidades e intensidades. 504 jovens, entre 11 e 20 anos, responderam o questionário de condutas anti-sociais e delitivas e de busca de sensação, de Arnett. Observou-se que a busca de intensidade e de novidades se relacionaram diretamente às condutas anti-sociais e delitivas. Esses resultados permitem supor que as variáveis personalísticas ainda têm bastante contribuição quando se pretende explicar a conduta juvenil delinqüente a partir da orientação de atitudes frente à excitação e ao investimento de atividades permeadoras de risco.

Palavras-chave: Comportamentos desviantes. Busca de sensação. Jovens.

Abstract: The youngsters behavior has been the target of interest in social and human science, mainly the behavior that permeates delinquency. Although countless variables can explain it, the construct seeking of sensation has contributed to this direction, for it gives emphasis to individual differences. Based on the perspective of the studies about personality, this work aims at the evaluation of the degree youngsters wish to take risks and the predisposition to novelty and to intense sensations. 504 youngsters from 11 to 20 years old answered the Arnett scale of the antisocial and criminal behaviors and sensation seeking. The results showed that the predisposition to experience intense sensations and novelty is capable of influencing youngsters to criminal and anti-social behavior.

Keywords: Delinquent behaviors. Sensation seeking. Youngsters.

Resumen: El estudio de las conductas juveniles, especialmente aquellas que conducen a la delincuencia, está despertando el interés de las ciencias sociales y humanas. Si bien se ha recurrido a numerosas variables para explicar tales conductas, el concepto de búsqueda de sensaciones está contribuyendo mucho en este sentido por el énfasis que pone sobre las diferencias individuales. Este concepto se refiere a la predisposición para vivir experiencias riesgosas y a la búsqueda de sensaciones nuevas e intensas. Una muestra integrada por 504 jóvenes, entre 11 y 20 años de edad, respondió el cuestionario de conductas antisociales y delictivas, y la escala de búsqueda de sensaciones de Arnett. Se observó que la búsqueda de intensidad y de novedad correlacionan directamente con las conductas antisociales y delictivas. Esos resultados permiten suponer que las variables de personalidad contribuyen significativamente cuando se pretende explicar la conducta juvenil delictiva a partir de las actitudes frente a la excitación y a la tendencia a involucrarse en actividades riesgosas. Palabras clave: Comportamientos desviados. Búsqueda de sensaciones. Jóvenes.

A problemática da delinqüência entre os jovens aponta espaços teóricos e empíricos para explicar os motivos que levam esse fenômeno a ser freqüentemente encontrado na dinâmica juvenil. Esse fato tem sido observado a partir do espaço social em que vivem os jovens, destacando-se o quanto eles têm investido em comportamentos impulsivos à procura de novas experiências. Porém, não há, necessariamente, problemas na manifestação desses comportamentos, pois essa busca faz parte da interação entre eles, como condição do desenvolvimento social. O problema surge quando tais experiências são vividas indiscriminadamente, tornando-se reveladoras de condutas tangenciadoras das normas e da organização social, sem um limite e tendendo ao risco pessoal e social.

Sendo assim, é no pulular dessas novas experiências indiscriminadas que algumas atitudes e comportamentos podem caracterizar apenas diversão ou a vida em grupos e assumir etiquetas da delinqüência juvenil e tornar-se, com isso, salientes: as formas de organização social que os jovens adotam - as gangs, a criação de jogos de diversão violentos, as balbúrdias em festas, o vandalismo e o alto consumo de álcool e fumo (Formiga \& Gouveia, 2003). Sob essa perspectiva, é 
possível, a partir desses conglomerados de eventos tangenciadores da norma social, compreendê-los através de duas dimensões: as condutas anti-sociais e as delitivas.

Ao considerar que um jovem apresenta esses tipos de conduta, seja anti-social ou delitiva, faz-se referência ao seu comportamento transgressor, com destaque não somente para os pobres, os negros, os de classe econômica mais baixa, etc., mas para qualquer jovem. Esse comportamento, segundo Formiga e Gouveia (2003), não tem, atualmente, forma específica, mas condutas de risco bastante evidentes; a conduta anti-social, por exemplo, refere-se à não conscientização das normas que devem ser respeitadas, desde a norma de limpeza das ruas ao respeito com os colegas. Nesse sentido, esse tipo de conduta caracteriza-se pelo fato de causar incômodo, sem, contudo, causar danos físicos as outras pessoas; referem-se portanto, apenas às travessuras dos jovens ou simplesmente à busca de romper algumas leis sociais.

A conduta delitiva diz respeito às ações do indivíduo que podem ser concebidas como merecedoras de punição, capazes de causar danos graves, morais e/ou físicos (Formiga \& Gouveia, 2003); portanto, tais condutas podem ser consideradas mais severas que as anteriores, representando uma ameaça eminente à ordem social em vigor. O que essas condutas têm em comum é que ambas interferem nos direitos e deveres das pessoas, ameaçando o seu bem-estar e diferenciandoas em função da gravidade das conseqüências delas oriundas. Possivelmente, todo jovem pratica ou já praticou algum tipo de conduta anti-social, o que faz parte do seu repertório sociocognitivo e constitui um desafio aos padrões tradicionais da sociedade, que coloca em evidência as normas da geração dos seus pais. Mas, quando não inibidas através de uma prática parental responsiva ou exigente, existe grande possibilidade de que esse desafio se converta em uma conduta delitiva (Formiga \& Gouveia, 2003).

As explicações para essas condutas têm indicado variáveis que apontam desde problemas da estrutura e funcionalidade da família, valores humanos e culturais, desenvolvimento moral, hábitos de lazer e estrutura e traços de personalidade à genética (Coelho, 2001; Formiga, Teixeira, Curado, Lüdke, \& Oliveira, 2003; Frias, Sotomayor, Varela, Zaragoza, Banda, \& García, 2000; Sobral, 1996). Apesar de apresentarem um poder explicativo e mérito quanto à direção para as soluções dessa situação entre os jovens, principalmente no que se refere aos fatores preditivos desse fenômeno, ainda tem sido promissor o poder explicativo das teorias personalísticas, independentemente da linha teórica que venham a defender, se idiográfica ou nomotética ${ }^{1}$, ou quanto ao seu foco filosófico em termos de esse construto ser inato ou adquirido (Benet-Martínez \& John, 1998; Gazzaniga \& Heatherton, 2005), o estudo da personalidade aponta não apenas uma dinâmica interna na psique do sujeito mas também uma perspectiva socializante quanto à formação e à estrutura da personalidade e à sua relação com as condutas humanas.

Essa linha de pesquisa na Psicologia, mesmo não sendo nova, tem sido retomada nos últimos dez anos, e acrescenta informações para a compreensão do comportamento humano, especificamente os comportamentos que conduzem à violência (anti-sociais e delitivos, comportamento agressivo, uso de drogas, etc.). Por sua vez, o estudo da personalidade, baseado na concepção dos traços (Formiga, 2002; Sobral, 1996; Stephenson, 1990), vem revelando, em relação ao modelo dos cinco grandes fatores da personalidade, 
evidências a partir de três áreas principais: análise fatorial de grandes conjuntos de termos lingüísticos relacionados com os traços e pesquisas interculturais, testando a universalidade das dimensões dos traços e a relação entre questionários de traços e outros questionários e avaliações. (Pervin \& John, 2004, p. 212)

A concepção da personalidade a partir dos traços não diz respeito

às questões patológicas, mas à díade genética/ meio ambiente, que implica características individuais consistentes do comportamento exibido pelo indivíduo em

diversas situações, características essas que são normalmente concebidas como disposições (Costa \& McCrae, 1992;

John, Donahue, \& Kentle, 1991; Saudino \& Plomin,

1996).
A concepção da personalidade a partir dos traços não diz respeito às questões patológicas, mas à díade genética/meio ambiente, que implica características individuais consistentes do comportamento exibido pelo indivíduo em diversas situações, características essas que são normalmente concebidas como disposições (Costa \& McCrae, 1992; John, Donahue, \& Kentle, 1991; Saudino \& Plomin, 1996). Com isso, são geradas taxonomias que permitem ao sujeito se expressar através das condutas, formas específicas para si e para os outros quando em interação social (Formiga, Yepes, \& Alves, 2005). Essa situação, na maioria das vezes, atende à desejabilidade social, a partir da qual o sujeito procura parecer melhor para os outros, descrevendo-se como gostaria que fosse descrito por quem o observa, justamente porque sua auto-imagem exigida se deve a uma co-dependência dos "papéis" sociais representados individualmente (Queiroga, Formiga, Jesus, Gouveia, \& Andrade, 2001). Vale destacar que não se pretende aprofundar, neste trabalho, uma discussão epistemológica sobre o estudo dos traços nas teorias da personalidade, pois não é esse o objetivo principal do presente estudo, além de ser possível encontrar discussões em diversos manuais de Psicologia sobre essa perspectiva (por exemplo, Allport, 1973; Díaz, 1998; Hampsom, 1986; Pervin \& John, 2004; Robinson, Shaver, \& Wrightsman, 1991). A título de lembrança, no presente estudo, pretende-se enfatizar a relação entre as condutas desviantes (anti-social e delitiva) e os traços de personalidade, especificamente, o construto busca de sensação.

\section{Os traços de personalidade e a conduta desviante: Um foco na busca de sensação}

A personalidade tem sido historicamente explorada como construto capaz de explicar as diferenças individuais, constituindo um marco teórico importante para os estudos a respeito das idiossincrasias do indivíduo e da estabilidade da conduta (Ávila, Rodríguez, \& Herrero, 1997; Barbaranelli \& Caprara, 1996), com a possibilidade de que, a partir das características individuais, avaliadas cientificamente ou em termos das crenças populares, seja possível, em situações e momentos variados, predizer reações ou disposições futuras (Gazzaniga \& Heatherton, 2005; Paunonen, 1998; Peabody, 1987; Trzop, 2000) das pessoas. Com isso, o conhecimento da personalidade não somente pode contribuir para a organização das relações interpessoais mas também para apontar os fatores de proteção para essas relações (McAdams, 1992).

Na literatura, é possível encontrar uma diversidade de estudos que enfatizam a relação entre a personalidade e a conduta humana, especificamente a que se destaca no presente estudo: a conduta desviante. Segundo Eysenck (1981), o jovem que apresenta uma conduta anti-social possui, em geral, traços de neuroticismo e impulsividade. Um resultado semelhante foi encontrado por Tranah, Harnett e Yule (1998) quando trataram da desordem de condutas, tendo esses autores identificado uma correlação positiva significativa de tal variável com os traços de psicoticismo e neuroticismo. Essas dimensões dos traços de personalidade enfatizam características 
individuais carregadas de emoções estáveis aliadas a afetos negativos e a comportamentos abertos a novas experiências.

Para Eysenck (1981), a inibição desse tipo de conduta, apesar de sua complexidade, seria possível apenas a partir da intervenção terapêutica (Ball, 2005; Frías et al., 2000). Apesar de tais resultados indicarem aspectos desestruturantes da personalidade, mesmo com base nos estudos dos traços, eles revelam um sujeito não sociável, emocionalmente negativo, possuidor de baixa auto-estima, entre outras características não socialmente adaptativas. Romero, Luengo e Sobral (2001) observaram, em jovens espanhóis sem história clínica, que as dimensões da personalidade de psicotismo, impulsividade, busca de sensação e extroversão estão fortemente correlacionadas com a quebra de normas sociais, o que indica que essas dimensões constituiriam um fator de risco para o comportamento anti-social.

Em estudo realizado por Heaven, Newbury e Wilson (2004), considerando a dimensão da escala de psicotismo de Eysenck em jovens não delinqüentes de 11 a 16 anos de idade, foi observado que a capacidade preditiva desse traço em relação à diversidade de comportamentos delinqüentes (por exemplo, uso de drogas, advertência policial e dano de propriedade, entre outros). Outro resultado semelhante foi encontrado por Formiga et al. $(2003,2005)$ ao considerarem a Teoria dos Cinco Grandes Fatores da Personalidade; esses autores observaram que as dimensões personalísticas de extroversão (relacionados à atividade e energia, à dominância e às emoções positivas) e abertura à mudança (comportamentos abertos a novas experiências, a experimentar coisas novas) explicavam, de modo positivo, as condutas anti-sociais e delitivas; por outro lado, as dimensões de agradabilidade (orientação prósocial com os demais, altruísmos, confiança) foram capazes de explicar, de modo negativo, as condutas desviantes; tais resultados estão de acordo com aqueles encontrados por Heaven (1996) e Tranah, Harnett e Yule (1998).

Apesar de tais estudos contribuírem para a explicação da conduta juvenil como uma tendência ou predisposição, a partir de alguns traços da personalidade avaliados por instrumentos como o 16-PF, NEO, PEN, OCEAN ou Cinco Grandes Fatores (Big Five) (Anastasi \& Rubina, 2000; Cordero, 1997; Engler, 1984), no Brasil, poucos são os estudos que enfatizam essa perspectiva bem como o construto busca de sensasão (Index Psi, 2006; Scielo, 2006), principalmente aqueles que avaliam o problema das condutas desviantes, em especial no que diz respeito à predisposição do jovem em viver intensamente as experiências, entendidas como busca de sensação, que podem convergir para um agir desviante.

O foco na perspectiva do traço personalístico da busca de sensação é apontado porque, na literatura em geral e no senso comum, considera-se que o jovem tenha a necessidade latente de expandir seu mundo ideal e "real" em termos do comportamento de reivindicação e instrumentalidade, esteja predisposto a convites pessoais ou sociais para viver novas descobertas e senti-las intensamente, podendo conceber que esses conglomerados comportamentais possam ser caracterizados como a busca de sensações (Arnett, 1994; Michel et al., 1999; Omar \& Uribe, 1998; Zuckerman, 1971). 
O construto busca de sensação teve seu estudo iniciado por Zuckerman (1971) e Zuckerman, Eysenck e Eysenck (1978), que a definia como uma necessidade de viver experiências complexas e de novidades apenas pelo desejo de afrontar riscos físicos e sociais, com o objetivo de satisfazer necessidades pessoais. Esse construto não é tido apenas como necessidade individual de experimentar situações de risco em termos da proposta por Zuckerman (1971), mas estaria inserido na socialização, que vem sendo avaliada enfaticamente, nos últimos anos, como condição sine quo non da construção da realidade social. Essa dimensão personalística, segundo Arnett (1994), pretende compreender o comportamento juvenil, principalmente aquele que caracteriza as transgressões de normas sociais, como as variações do comportamento de risco a partir da investida que o jovem dá à busca de novas experiências e emoções intensas (Mussen, Conger, Kagan, \& Huston, 1995).

Arnett (1994), a partir da perspectiva de M. Zuckerman, fazendo referência a alguns limites tanto na concepção do construto quanto na instrumentalização e na seleção dos itens, propôs um modelo alternativo, no qual afirma que a busca de sensação varia entre intensidade e novidade, e não apenas em termos de complexidade comportamental, como concebia Zuckerman. Essa dimensão do traço de personalidade deveria ser enfatizada quanto ao processo de socialização, que tornaria capaz de modificar as predisposições biológicas, respondendo ao dilema genética-ambiente. Outro aspecto apontado por Arnett é que a busca de sensação se desenvolve a partir do interesse por experiências novas e intensas, e não, necessariamente, em correr riscos (Omar \& Uribe, 1998). Ao considerar essas variáveis, é possível apresentar mais uma peça no quebra-cabeça do problema da delinqüência, principalmente em relação aos construtos que avaliam traços de personalidade, os quais têm oferecido respostas significativas entre elas.

Donohew et al. (1999), a partir de instrumento de Zuckerman que avalia a busca de sensação, observaram que o sujeito que apresenta maior busca de sensação terá maior probabilidade de começar a usar drogas e de iniciar esse uso numa idade mais baixa. Por outro lado, os que têm baixos níveis de sensação possivelmente se tornarão usuários regulares. Isto permite uma reflexão sobre a associação entre risco e ilegalidade, em relação a alta busca de sensação (Omar \& Uribe, 1998), condição essa que, independe do grau de experimentação dessas sensações, aponta-se para uma predisposição em revelar as condutas permeadoras da delinqüência. No estudo de Heaven (1996) com o inventário da personalidade NEO, a dimensão excitação-busca de sensação serviu como preditora tanto do vandalismo quanto da violência interpessoal. Para Romero, Luengo e Sobral (2001), além de outras dimensões da personalidade, a busca de sensação esteve fortemente relacionada à quebra de normas sociais pelos jovens. Dessa maneira, de acordo com as evidências obtidas nos estudos até aqui considerados, o objetivo principal do presente estudo foi avaliar a relação entre a busca de sensação em relação à novidade e à intensidade e as condutas anti-sociais e delitivas em jovens, esperando que as dimensões da busca de sensação - novidade e intensidade - se relacionem positivamente com as condutas desviantes (anti-social e delitiva). 
Material e método

Amostra

A amostra foi composta por 504 jovens, distribuídos igualmente no nível escolar fundamental e médio da rede privada e pública de educação na cidade de Palmas TO, com idades entre 14 e 21 anos e uma renda econômica média de $\mathrm{R} \$ 1.160,00$. Os respondentes pertenciam a ambos os sexos, predominando ligeiramente a participação de mulheres (53\%). Tal amostra foi não probabilística, ou seja, foi intencional, pois o propósito era, principalmente, garantir a validade interna dos resultados da pesquisa.

Instrumento

Os participantes responderam um questionário composto das seguintes medidas:

\section{Escala de Condutas Anti-sociais e Delitivas:}

esse instrumento, proposto por Seisdedos (1988) e validado por Formiga (2002) e Formiga e Gouveia (2003) para o contexto brasileiro, compreende uma medida comportamental em relação às condutas anti-sociais e delitivas. Tal medida é composta por 40 elementos, distribuídos em 2 fatores, como se segue: o primeiro envolve as condutas anti-sociais, em que seus elementos não expressam delitos, mas comportamentos que desafiam a ordem social e infringem as normas sociais (por exemplo, jogar lixo no chão mesmo quando há perto um cesto de lixo; tocar a campainha na casa de alguém e sair correndo). O segundo fator relacionase às condutas delitivas. Estas incluem comportamentos delitivos que estão fora da lei, que caracterizam uma infração ou uma conduta faltosa e prejudicial a alguém ou mesmo à sociedade (por exemplo, roubar objetos dos carros; conseguir dinheiro ameaçando pessoas mais fracas). Para cada elemento, os participantes deveriam indicar o quanto apresentava o comportamento assinalado no seu dia a dia. Para isso, utilizavam uma escala de resposta com 10 pontos, tendo os seguintes extremos: $0=$ Nunca e 9 = Sempre.

A presente escala revelou indicadores psicométricos consistentes para identificar os fatores destacados acima; para a conduta anti-social, encontrou-se um Alpha de Cronbach de 0,86, e a conduta delitiva ou delinqüente, 0,92. Considerando a análise fatorial confirmatória, realizada com o Lisrel, 8.0, foram comprovadas essas dimensões previamente encontradas $\left(x^{2} / g \mathrm{l}=1,35\right.$; AGFI=0,89; $\mathrm{PHI}(\phi)=0,79, p>0,05)$ na análise dos principais componentes (Formiga \& Gouveia, 2003).

Inventário de Busca de Sensação: construído por Arnett (1994) e Omar e Uribe (1998), trata-se de uma escala composta por 20 itens, que compõem duas sub-escalas referentes à busca de intensidade (por exemplo, "quando escuto música, eu gosto de escutá-la bem alto"; "gosto de assistir filmes onde tem muita explosão e batidas"; "deve ser muito excitante estar brigando numa guerra") e novidade (por exemplo, "seria interessante casar-me com alguém de um país estrangeiro"; "penso que é divertido falar, atuar ou se mostrar mesmo da frente das pessoas"; "gostaria muito de viajar para lugares distantes e desconhecidos") na estimulação dos sentidos, com 10 itens cada fator. No Brasil, foram observadas dimensões semelhantes desse construto (Omar, Aguiar, 
\& Formiga, 2005). A pessoa responderia utilizando uma escala de resposta tipo Likert, com quatro pontos (1 = não me descreve em nada; 2 = descreve-me em alguma medida; 3 = descreve-me bem e $4=$ descreve-me totalmente) devendo indicar nesta o quanto cada um dos itens descreve sua conduta habitual.

Caracterização sociodemográfica: foram elaboradas perguntas que contribuíram para caracterizar os participantes deste estudo (por exemplo, sexo, idade, classe social) bem como para realizar o controle estatístico de algum atributo que pudesse interferir diretamente nos seus resultados.

\section{Procedimento}

Procurou-se definir um mesmo procedimentopadrão, que consistia em aplicar os instrumentos coletivamente em sala de aula, em escolas de diversas áreas urbanas da cidade de Palmas-TO. Dessa forma, colaboradores com experiência metodológica e ética ficaram responsáveis pela coleta dos dados. Após conseguir a autorização, tanto da diretoria da escola quanto dos professores responsáveis pela disciplina, os aplicadores se apresentavam em sala de aula como pessoas interessadas em conhecer as opiniões e os comportamentos das pessoas no cotidiano, solicitando a colaboração voluntária dos estudantes no sentido de responderem um breve questionário. Para isso, foi-lhes dito que não havia respostas certas ou erradas, e que, mesmo sendo necessária uma resposta individual, estes não deveriam ser obrigados a respondê-la, podendo desistir a qualquer momento, quando recebessem o instrumento ou ao iniciar a leitura bem como em outra eventual condição, não havendo problema em sua desistência.

A todos era assegurado o anonimato das respostas, enfatizando que elas seriam tratadas estatisticamente em seu conjunto; apesar de o questionário ser auto-aplicável e contar com as instruções necessárias para que pudesse ser respondido, os colaboradores estiveram presentes durante toda a aplicação para esclarecer eventuais dúvidas, o que não interferiu na lógica e na compreensão das respostas dos respondentes. Um tempo médio de 30 minutos foi suficiente para concluir essa atividade. Quanto à análise dos dados, utilizou-se o pacote estatístico SPSSWIN, em sua versão 11.0, para tabular e realizar as análises de estatísticas descritivas e os coeficientes de correlação $r$ de Pearson.

\section{Resultados e discussão}

Atendendo o objetivo principal do presente estudo - conhecer a relação entre condutas anti-sociais e delitivas e a busca de sensação de novidade e intensidade - efetuou-se uma correlação de Pearson. Mas, antes de discorrer a respeito do que foi pretendido, procurou-se avaliar a relação interna entre os construtos estudados. Assim, observouse que as dimensões de ambas as variáveis, individualmente, estiveram inter-relacionadas, como, por exemplo: a busca de sensação de novidade e intensidade $(r=0,42 ; p<0,001)$ se relacionara tanto entre si quanto com o somatório total desse construto, denominado busca de sensação (BS) (respectivamente, $r=0,40, r=0,38 ; p<0,001)$. O mesmo ocorreu com as condutas anti-sociais e delitivas ( $r=0,94 ; p<0,001)$, sendo que estas se relacionaram com o somatório total dessas 
condutas (chamado de condutas desviantes - $C A D$ ), apresentando correlações com as condutas anti-sociais $(r=0,64 ; p<0,001)$ e delitivas $(r=0,54 ; p<0,001)$.

Para cada um dos construtos, é mantida uma interdependência em suas dimensões. Com isso, se os jovens apresentarem maior pontuação em um dos fatores, provavelmente obterão uma pontuação alta nos demais. Essa reflexão vale tanto para as condutas desviantes quanto para a busca de sensação.

Pretendendo responder ao objetivo principal deste estudo, a partir de uma correlação de Pearson (ver tabela 1), observou-se que a busca de sensação de intensidade se relacionou diretamente com as condutas anti-sociais $(r=0,33, p<0,001)$ e delitivas $(r=0,25, p<0,001)$. Também foi encontrada correlação semelhante, e na mesma direção, para a busca de sensação de novidade e para a conduta anti-social e delitiva, respectivamente $(r=0,18 ; r=0,14$; todas com $p<0,001)$. Na mesma direção de raciocínio, observou-se que o construto busca de sensação (BS - somatório total dos itens do inventário) se relacionou com as condutas anti-sociais $(r=0,30, p<0,001) \mathrm{e}$ delitivas $(r=0,23, p<0,001)$. O mesmo ocorreu com as condutas desviantes (CAD - somatório total dos itens da escala) que se correlacionaram positivamente com a busca de sensação de novidade $(r=0,18, p<0,001)$ e de intensidade $(r=0,32, p<0,001)$. Como é possível perceber, o construto que avalia o grau com que os jovens pretendem viver experiências que incluem riscos e a sua predisposição à sensação, tanto considerando uma escala unifatorial (BS) bem como as suas específicas dimensões (busca de novidade e intensidade), foram capazes de explicar as condutas desviantes (CAD) e suas variações - anti-social e delitiva.

Tabela 1. Correlações das dimensões da busca de sensação e as condutas anti-sociais e delitivas em jovens.

\begin{tabular}{lccccc}
\hline & \multicolumn{5}{c}{ TIPO DE CONDUTA } \\
BUSCA DE SENSAÇÃO & $M$ & $D P$ & Anti-social & Delitiva & CAD \\
\hline Intensidade & 2,44 & 0,67 & $0,33^{*}$ & $0,25^{*}$ & $0,32^{*}$ \\
Novidade & 2,68 & 0,7 & $0,18^{*}$ & $0,14^{*}$ & $0,18^{*}$ \\
Busca de sensação (BS) & 2,56 & 0,61 & $0,30^{*}$ & $0,30^{*}$ & $0,29^{*}$ \\
\hline
\end{tabular}

* $p<0,001$ (teste unilateral; eliminação pairwise de casos em branco); CAD = Pontuação total das condutas anti-sociais e delitivas. \# BS = Pontuação total da busca de sensação

Tomando como dado adicional, a partir de uma análise descritiva, pretendeu-se avaliar o grau de busca de sensação da intensidade e novidade e a influência na pontuação média das condutas anti-sociais e delitivas. Observou-se que, quanto maior a investida por parte desses jovens na busca de sensação de intensidade, maior a probabilidade de apresentarem condutas anti-sociais $(60 \%)\left(\chi^{2} 1=26,60 ; p<0,01\right)$ e delitivas $(66 \%)\left(\chi^{2} 1=29,25 ; p<0,01\right)$. O mesmo ocorreu com a busca de novidade, porém com uma interpretação inversa para cada conduta desviante, pois, 
para mais de $60 \%\left(\chi^{2} 1=23,13 ; p<0,01\right)$ dos jovens que apreciaram viver a busca de novidade, maior a probabilidade de manifestarem uma conduta anti-social; por outro lado, para $56 \%$ dos jovens que não investem nesse tipo de sensação, menor a probabilidade de apresentarem a conduta delitiva $\left(\chi^{2} 1=12,24 ; p<0,01\right)$. Por fim, no que diz respeito à conduta desviante CAD (somatório total dos itens da escala) - 68\% do jovens que nunca apresentaram esse tipo de conduta tiveram menor busca de intensidade, bem como, em $61 \%$ desses jovens, observou-se uma baixa busca de novidade $\left(\chi^{2} 1=8,09 ; p<0,01\right)$.

Tabela 2. Freqüência em percentagem da busca de intensidade e novidade em relação às condutas anti-sociais e delitivas.

\begin{tabular}{|c|c|c|c|c|c|c|c|}
\hline \multirow[b]{3}{*}{ BUSCA DE SENSAÇÃO } & & \multicolumn{6}{|c|}{ TIPO DE CONDUTA } \\
\hline & & \multicolumn{2}{|c|}{ Anti-social } & \multicolumn{2}{|c|}{ Delitiva } & \multicolumn{2}{|c|}{ Desviante } \\
\hline & & Nunca & Sempre & Nunca & Sempre & Nunca & Sempre \\
\hline \multirow{2}{*}{ Intensidade } & Nunca & 60 & 40 & 61 & 39 & 68 & 31 \\
\hline & Sempre & 35 & 64 & 34 & 66 & 38 & 61 \\
\hline \multirow{2}{*}{ Novidade } & Nunca & 58 & 42 & 54 & 46 & 61 & 39 \\
\hline & Sempre & 40 & 60 & 47 & 52 & 46 & 54 \\
\hline
\end{tabular}

Como dado adicional, avaliou-se a diferença entre as médias de homens e mulheres em relação ao construto busca de sensação e condutas desviantes. No gráfico 1, é possível visualizá-las: no que diz respeito à busca de intensidade, especificamente, os homens apresentaram uma média superior $(M=2,58, D P=0,65)$ à das mulheres $(M=2,30, D P=0,67)[\mathrm{t}(403)=4,25, p<0,01]$; em relação à busca de novidade, os homens também pontuaram mais alto $(M=2,78, D P=0,75)$ do que as mulheres $(M=2,60, D P=0,64)[t(404)=2,25, p<0,01]$. Esses resultados se assemelham aos encontrados por Omar e Uribe (1998), que também observaram que os homens apresentaram médias superiores à das mulheres em ambas as dimensões da busca de sensação. Além da diferença entre sexo e busca de sensação, observou-se que esses jovens, considerando uma média geral, são mais predispostos, hierarquicamente, à busca de novidade seguida de intensidade, tendo a primeira dimensão apresentado média superior, respectivamente, ( $M_{\text {busca de novidade }}=2,68$, $D P=0,70)$ e $\left(M_{\text {busca de intensidade }}=2,44, D P=0,67\right)$.

No mesmo gráfico 1, no que diz respeito à conduta anti-social $I_{\llcorner}$os homens apresentaram média superior $(M=1,70, D P=1,42)$ à das mulheres $(M=1,26, D P=1,22)$ [t(431)=3,42, $p<0,01]$; o mesmo foi encontrado para as condutas delitivas, na qual os homens pontuaram mais alto $(M=1,03, D P=1,32)$ do que as mulheres $(M=0,67, D P=1,09)$ [t(428)=3,12, $p<0,01]$. Esse fato foi visto, também, na conduta desviante (CAD = Pontuação total das condutas anti-sociais e delitivas), em que os homens apresentaram médias superiores $(M=1,36, D P=1,31)$ às das mulheres $(M=0,96, D P=1,17)[\mathrm{t}(414)=3,38, p<0,01]$.

Esses resultados corroboram os já encontrados em um estudo pioneiro por Formiga (2002), os quais se assemelham entre si. Seus resultados diferem de fato em relação ao gênero, pois este 
não somente pode ser refletido em termos da administração quanto do desenvolvimento físico, psíquico e social, bem como, junto às perspectivas de manutenção de estereótipos estabelecidos nas relações interpessoais que orientam a conduta juvenil, traços personalísticos que garantem, em determinadas situações, o controle, ou não, dessas experiências psicossociais, considerando sociocognitivamente o que é adequado para homem e para mulher.

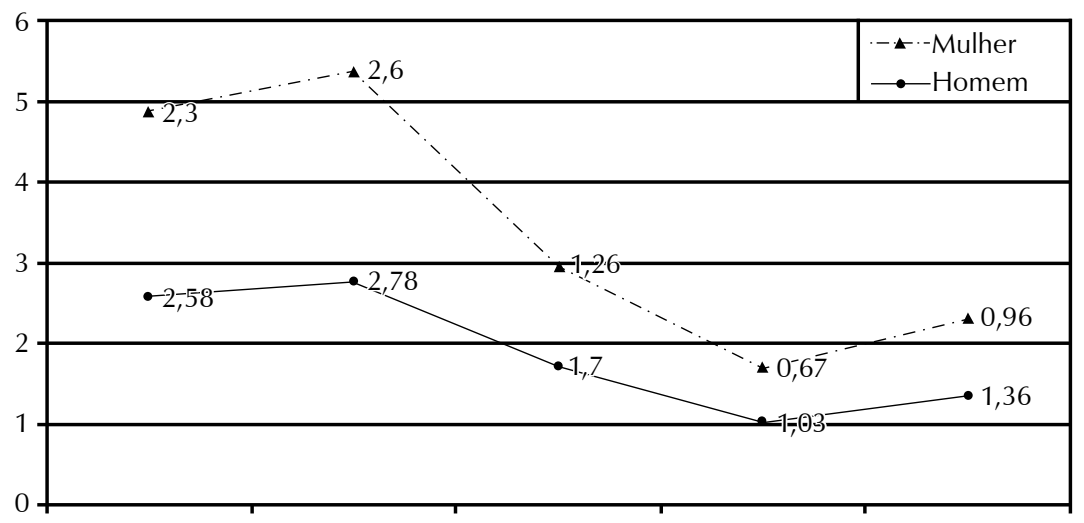

Figura 1. Diferença entre homens e mulheres em relação à busca de sensação e à conduta desviante.

Com isso, pode ser observada a contribuição dos construtos personalísticos na explicação das condutas permeadoras da delinqüência. Ao considerar esse novo construto - a busca de sensação - pretende-se destacar não somente a perspectiva individual mas também o processo de socialização em que esse construto é formado (Omar \& Uribe, 1998) e investido na dinâmica juvenil. Assim, pode-se inferir que a conduta desviante, seja ela anti-social, seja delitiva, não teria seu foco apenas no sujeito e na organização dos traços de personalidade, mas que essas condutas seriam salientadas e influenciadas a partir da administração e socialização que os traços da busca de sensação estivessem envolvidos nas relações de afiliação endogrupal, isto é, a capacidade com o sujeito se organiza a partir da identidade com os pares (colegas, vizinhos, etc.) ou com os responsáveis pela manutenção de uma conduta convencional (pais, professores, etc.).

Essa reflexão foi reconhecida por Formiga, Yepes e Alves (2005) ao relacionaram os Cinco Grandes Fatores da Personalidade e a afiliação endogrupal. Segundo esses autores, quanto maior a identidade que os jovens venham ter com pais e professores, maior a relação com traços de agradabilidade (que reflete a orientação pró-social com os demais, altruísmo, confiança) e conscienciosidade (que envolve o controle de impulsos com a finalidade de obter realizações, podendo-se incluir aqui o traço responsabilidade); por outro lado, quanto maior a identidade com os colegas de bairro, da escola, namorado(a), maior a probabilidade de se apresentarem traços de extroversão (relacionados à atividade e energia, dominância e emoções positivas) e abertura à mudança (diz respeito ao comportamento aberto a novas experiências, a experimentar coisas novas). Dessa forma, aponta-se em direção das concepções de Gazzaniga e Heatherton (2005) e Cloninger (1999), para os quais, com base nos estudos de Walter Michel a respeito da perspectiva situacionista na formação e na mudança contextual nos traços de personalidade, a variação na busca de sensação é capaz de predizer os comportamentos, quando se leva em consideração as disposições individuais e a influência interacional, em via de mão dupla. 
De fato, se se pensar nessa direção, pode-se concluir que esses jovens não serão capazes, simplesmente, de procurarem eventos que os levem a sentir sensações de novidade ou intensidade no vazio, como algo que surgisse do nada, ou apenas como condição de organização hormonal, estímulo ou até mesmo, e apenas, como uma influência social. Mesmo sendo a quebra de uma norma ou estando desinformados do perigo do evento em que irão se envolver, esses jovens terão, de acordo com Omar e Uribe (1998), uma convergência entre as características individuais e o processo socializador.

Com isso, ao se considerar um comportamento delinqüente, com base nesses resultados (ver Tabela 1), esse terá probabilidade de ocorrer se o sujeito vier a apresentar maior tendência para a busca de novidade e intensidade não somente devido a sua disposição para tal experiência mas também devido à influência do contexto que o persuade a viver indiscriminadamente, a experimentar uma vivência à "flor da pele" ou uma aventura qualquer, isto é, a estar em um estado intenso em que se vive o momento.

Sendo assim, de acordo com a Tabela 2, que revela que, quanto maior a predisposição à busca de intensidade e novidade, maior a probabilidade de que o jovem venha a apresentar condutas anti-sociais e delitivas. Essa perspectiva é bem observada e discutida entre os jovens, o que os torna, perceptivamente, possuidores de comportamentos conturbados e atitudes inconseqüentes, em que, algumas vezes, eles estão entregues aos impulsos próprios dessas sensações (Fraga, 2000), que, necessariamente, podem não apontar em direção ao risco, mas, pela motivação socializante que ocorre entre os jovens o de terem comportamento inclinado à quebra das normas sociogeracionais - como uma condição que faz parte do período de desenvolvimento em que se encontram.

Dessa maneira, é possível que, ao ser intensificada a comprovação da identidade adolescente com os pares, uma simples conduta social decorrente da diversão ou das relações com os pares de iguais poderá desencadear condutas que levem à delinqüência, condição essa que permite, justamente, refletir sobre a influência desses grupos na desinibição dos jovens, não sendo caracterizado que os jovens desejem correr um risco social e psicológico, mas apenas que desejem experimentar um momento em que poderão viver novas experiências de vida.

Tanto a influência da mídia em geral quanto a dos familiares, que incentivam os jovens a viver, intensa e insistentemente, a relação e o "envolvimento" com as pessoas, experimentando ou procurando experimentar situações novas que visam à "valorização e à preparação" para a vida, estas, por sua vez, camufladas no discurso do amadurecimento psicológico e social, imbuído numa espécie de rito de passagem, provavelmente permitiriam a esses garotos a construção e a manutenção de repertórios das condutas de risco.

Por fim, apesar de este estudo consistir em uma pequena contribuição, dentre as muitas existentes, para a compreensão do comportamento desviante dos jovens bem como em refletir a relação situaçãodisposição, especificamente no que se refere à explicação para o comportamento humano, ao considerar que as pessoas nas suas relações geralmente conhecem a pessoa e o ambiente em que ela vive e influenciam, assim, a sua maneira de agir, o objetivo do trabalho é o de promover certa proteção para esse tipo de contexto, principalmente quando está inserida a conduta desviante. 
Porém, alguns limites devem ser destacados, pois não se pretende responder definitivamente ao problema do comportamento desviante juvenil; seria de grande benefício, por exemplo, 1 - um estudo com as mesmas variáveis entre grupos juvenis institucionalizados e não institucionalizados; 2 - a avaliação da relação e da variação da pontuação média desses construtos a partir do status econômico e da dinâmica familiar; 3 - a realização de estudo com as mesmas variáveis a fim de avaliar os diferentes contextos da socialização familiar e escolar, comparando-as quanto ao regime institucional mais coercitivo ou mais permissivo; 4 - comparações entre estudos com avaliações clínicas e experimentais quanto à busca de sensação e à predição do comportamento entre pais e filhos.

\section{Nilton Soares Formiga*}

Mestre em Psicologia social pela Universidade Federal da Paraíba. Atualmente, é doutorando na mesma Universidade.

\section{Marcos Aguiar}

Doutor em Psicologia pela Universidade Federal do Rio de Janeiro e professor/pesquisador da UFRJ-Rural

\section{Alicia Omar}

Doutora em Psicologia, pesquisadora independente do CONICET (Consejo Nacional de Investigaciones Científicas y Técnicas), Argentina.

E-mail: agomar@arnet.com.ar

\section{* Endereço para envio de correspondência:}

Rua Juiz Ovídio Gouveia, 185 Pedro Gondim. João Pessoa - PB - Brasil CEP 58031-030

E-mail: nsformiga@yahoo.com.br

Recebido 24/05/2007 Reformulado 06/08/2008 Aprovado 07/08/2008

Allport, G. W. (1973). Personalidade: padrões e desenvolvimento. São Paulo: EPU.

Anastasi, A., \& Rubina, S. (2000). Testagem psicológica. Porto Alegre: Artmed.

Arnett, J. (1994). Sensation seeking: A new conceptualization and a new scale. Personality and Individual Differences, 2(16), 289-296.

Ávila, A. E., Rodríguez, S. C., \& Herrero, J. R. S. (1997). Evaluación de la personalidad patológica: nuevas perspectivas. In $\mathrm{E}$. Cordero (Ed.), La evaluación psicológica en el año 2000 (pp. 79-107). Madrid: TEA.

Ball, S. A. (2005). Personality traits, problems, and disorders: Clinical applications to substance use disorders. Journal of Research in Personality, 39, 84-102.

Barbaranelli, C., \& Caprara, G. V. (1996). How many dimensions to describe personality? A comparison of Cattel, Comrey, and the Big Five taxonomies of personality traits. European Review of Applied Psychology, 46(1), 15-24.
Benet-Martínez, V., \& John, O. P. (1998). Los cinco grandes across cultures and ethnic groups: Multitrait multimethod analyses of the Big Five in Spanish and English. Journal of Personality and_Social Psychology, 75, 729-750.

Cloninger, S. C. (1999). Teorias da personalidade. São Paulo: Martins Fontes.

Coelho Jr., L. L. (2001). Uso potencial de drogas em estudantes do ensino médio: suas correlações com as prioridades axiológicas. Dissertação de Mestrado em Psicologia Social, Universidade Federal da Paraíba, João Pessoa.

Cordero, E. (1997). La evaluación psicológica en el año 2000. Madrid: TEA.

Costa, P. T., \& McCrae, R. R. (1992). Four ways five factors are basic. Personality and Individual Differences, 13, 653-665.

Díaz, L. R. (1998). Cultura y personalidad: rasgos universales e idiosincrásicos. In Alcaraz, \& A. Bouzas (Eds.), Las aportaciones mexicanas a la psicología (pp. 631-652). México: UNAM. 
Donohew, R. L., Hoyle, R. H., Clayton, R. R., Skinner, W. F., Colon, S. E., \& Rice, R. E. (1999). Sensation seeking and drug use by adolescents and their friends: Models for marijuana and alcohol. Journal of Studies on Alcohol, 60(5), 622-640.

Engler, B. (1984). Personality theories: An introduction. Boston, MA: Houghton Mifflin.

Eysenck, H. J. (1981). Impulsiveness and anti-social behavior in children. Current Psychological_Research, 1, 31-37.

Formiga, N. S. (2002). Condutas anti-sociais e delitivas: uma explicação baseada nos valores humanos. Dissertação de Mestrado em Psicologia Social, Universidade Federal da Paraíba, João Pessoa.

Formiga, N. S., \& Gouveia, V. V. (2003). Adaptação e validação da escala de condutas anti-sociais e delitivas ao contexto brasileiro. Psico (Porto Alegre), 34(2), 367-388.

Formiga, N. S., Teixeira, J., Curado, F., Lüdke, L., \& Oliveira, A. R. N. (2003). A predição das condutas anti-sociais e delitivas a partir dos traços de personalidade (p. 381). In Resumos, XXXIII Reunião Anual da Sociedade Brasileira de Psicologia. Psicologia: Compromisso com a Vida. Belo Horizonte: Sociedade Brasileira de Psicologia.

Formiga, N. S., Yepes, C., \& Alves, I. (2005). Correlatos entre traços de personalidade e afiliação com pares sociais: reflexões a respeito da formação personalística em jovens (pp. 277-279). In Anais do IV Congresso Científico do Ceulp-Ulbra: Ética e Ciência. Palmas, TO.

Fraga, A. B. (2000). Corpo, identidade e bom mocismo: o cotidiano de uma adolescência bem comportada. Belo Horizonte: Autêntica.

Frías, M. A., Sotomayor, M. P., Varela, C. B. C., Zaragoza, F. O., Banda, A. L. B., \& García, A. S. (2000). Predictores de la delincuencia juvenil. La Psicología Social en México, (8), 486-492.

Gazzaniga, M. S., \& Heatherton, T. F. (2005). Personalidade. In Ciência psicológica: mente, cérebro e comportamento (pp. 470-496). Porto Alegre: Artmed.

Hampsom, S. E. (1986). El concepto de personalidad. In La construcción de la personalidad (pp. 11-16). Espanha: Piados.

Heaven, P. C. L. (1996). Personality and self-reported delinquency: Analysis of the "big five" personality dimensions. Personality and Individual Differences, 20(1), 47-54.

Heaven, P. C. L., Newbury, K., \& Wilson, V. (2004). The Eysenck psychoticism dimension and delinquent behaviours among non criminals: Changes across the lifespan? Personality \& Individual Differences, 36, 1817-1825.

Index Psi. (2006). Delinqüência, jovens e busca de sensação. Recuperado em 15 de abril de 2006, de http: \www. indexpsi.org.br

John, O. P., Donahue, E. M. \& Kentle, R. L. (1991). The "Big Five" Inventory - Versions 4a and 54. Berkeley: University of California; Berkeley: Institute of Personality and Social Research.

MCAdams, D. P. (1992). The five-factor personality profiles. Journal of Personality Assesssment, 60, 329-361.
Michel, G., Mouren-Siméoni, M-C., Perez-Diaz, F., Falissard, B. Carton, S., \& Jouvent, R. (1999). Construction and validation of a sensation seeking scale for adolescents. Personality and individual_differences, 26, 159-174.

Mussen, P. H., Conger, J. J., Kagan, J. E., \& Huston, A. C. (1995). Desenvolvimento e personalidade da criança (3a ed.). São Paulo: Harbra.

Omar, A., \& Uribe, H. D. (1998). Dimensiones de personalidad y busqueda de sensaciones. Psicologia: Teoria, Investigação e Prática, v. 3, 257-268.

Omar, A., Souza, M. A. \& Formiga, N. S. (2005). Generalização transcultural de um modelo de busca de sensações: um estudo Argentina-Brasil. In: Anais XXXV reunião anual de psicologia. Curitiva- PR. [Resumos].

Paunonen, S. V. (1998). Hierarchical organization of personality and prediction of behavior. Journal of Personality and Social Psychology, n. 2, v. 74, 538-556.

Peabody, D. (1987). Personality dimensions through trait inferences. Journal of Personality and_Social Psychology, n. 2, v. $46,384-403$

Pervin, L. A., \& John, O. P. (2004). Personalidade : Teoria e pesquisa Porto Alegre : Artmed.

Queiroga, F., \& Formiga, N. S., Jesus, G. R., Gouveia, V. V., \& Andrade, J. M. (2001). Desejabilidade social e personalidade. XXXI Reunião Anual de Psicologia: A Construção da Psicologia na Pesquisa e no Ensino. (p. 306). Rio de Janeiro: SBP.

Robinson, J. P., Shaver, P. R., Wrightsman, L. S. (1991). Measures of personality and social psychological attitudes. (Vol. 1, pp. 661-753). San Diego, CA: Academic Press.

Romero, E., Luengo, M. A., \& Sobral, J. (2001). Personality and antisocial behavior: Study of temperamental dimensions. Personality and Individual Differences, v. 31, 329-348.

Saudino, K. J., \& Plomin, R. (1996). Personality and behavior genetics: Where have been and where are we going? Journal of Research in Personality, 30, 335-347.

Scielo. (2006). Delinqüência, jovens e busca de sensação. Recuperado em 30 de junho de 2006, de http: \www. scielo.br

Seisdedos, N. C. (1998). Cuestionario A - D de conductas antisociais - delictivas. Madri: TEA.

Sobral, J. (1996). Psicología social jurídica. In J. L. Álvaro, A. Garrido, \& J. R. Torregrossa (Eds.), Psicología social aplicada (pp. 254-268). Madrid: McGraw-Hill.

Stephenson, G. F. (1990). Psicología social aplicada. In: M. Hewstone, W. Stroebe, J. P. Codol, \& G. M. Stephenson (Eds), Introducción a la psicología social: una perspectiva europea (pp. 397-425). Barcelona: Ariel.

Tranah, T., Harnett, P. E, \& Yule, W. (1998). Conduct disorde and personality. Personality and Individual Differences, 24 741-745.

Trzop, B. M. (2000). The big five: Taxonomy of trait theory. Recuperado em 24 de dezembro de 2005, de http//www. personality research.org/papers/popkins.html

Zuckerman, M. (1971). Dimensions sensation of seeking. Journal of Consulting and Clinical Psychology, 36, 45-52.

Zuckerman, M., Eysenck, S. B. G., \& Eysenck, H. J. (1978). Sensation seeking in England and America: Cross-cultural, age and sex comparisons. Journal of Consulting and Clinical Psychology, 46, 139-149. 